\title{
Innervation options for gracilis free muscle transfer in facial reanimation
}

\author{
Katherine Gossett ${ }^{1}$, David Chen ${ }^{2}$, Myriam Loyo ${ }^{3}$ \\ 'Department of Otolaryngology - Head and Neck Surgery, Medical University of South Carolina, Charleston, SC 29425, USA. \\ ${ }^{2}$ Division of Facial Plastic and Reconstructive Surgery Department of Otolaryngology - Head and Neck Surgery, University of \\ Arizona, Tuscon, AZ 85724, USA. \\ ${ }^{3}$ Division of Facial Plastic and Reconstructive Surgery, Department of Otolaryngology - Head and Neck Surgery, Oregon Health \& \\ Science University, Portland, OR 97239, USA.
} Correspondence to: Dr. David Chen, Division of Facial Plastic and Reconstructive Surgery, Department of Otolaryngology - Head
and Neck Surgery, University of Arizona, 1501 N. Campbell Avenue, Tuscon, AZ 85724, USA. E-mail: chenda@musc.edu

How to cite this article: Gossett K, Chen D, Loyo M. Innervation options for gracilis free muscle transfer in facial reanimation. Plast Aesthet Res 2021;8:60. https://dx.doi.org/10.20517/2347-9264.2021.69

Received: 18 Jun 2021 First Decision: 20 Aug 2021 Revised: 11 Sep 2021 Accepted: 20 Oct 2021 Published: 5 Nov 2021

Academic Editors: Mark K. Wax, Ruben Yap Kannan Copy Editor: Xi-Jun Chen Production Editor: Xi-Jun Chen

\begin{abstract}
Gracilis free muscle transfer (GFMT) is considered the gold standard in dynamic smile reanimation in patients with long-standing facial paralysis. There are multiple motor nerves in the head and neck that can be used to provide innervation to the GFMT, either alone or in combination. In this article, we review the literature about these donor nerve options and discuss their advantages and disadvantages in terms of smile excursion, spontaneity, reliability, and timing. Furthermore, we discuss the use of multiple donor nerve sources in dually-innervated GFMT and areas for future investigation.
\end{abstract}

Keywords: Facial paralysis, facial reanimation, gracilis free muscle transfer, masseteric nerve, cross facial nerve graft

\section{INTRODUCTION}

Facial paralysis is a devastating condition that can lead to significant psychological distress and functional and aesthetic impairment ${ }^{[1]}$. The management of facial paralysis focuses on restoring symmetry to the face at rest and with facial expressions. In the lower face, smile restoration is a key element of dynamic facial 
reanimation. In cases of long-standing facial paralysis, typically greater than 12 months, atrophy of the native mimetic facial muscles precludes nerve transposition, which relies on reinnervation of the native facial musculature. This applies similarly to congenital facial nerve palsy cases in which the facial nerve and muscles may be absent. In such cases, gracilis free muscle transfer (GFMT) is widely accepted as the gold standard in dynamic smile restoration [Figure 1$]^{[2]}$.

One critical aspect of this procedure is the selection of a motor nerve or nerves to innervate the GFMT. In its original description by Harii et al. ${ }^{[2]}$ in 1976, the deep temporal nerve was used as the donor source of innervation. Since then, various other donor nerves have been described in the literature, including the cross facial nerve graft $(\mathrm{CFNG})^{[3-6]}$, masseteric nerve $\mathrm{e}^{[7-11]}$, hypoglossal nerve ${ }^{[12,13]}$, spinal accessory nerve $(\mathrm{SAN})^{[6,13]}$, and combinations ${ }^{[14-17]}$ of the above. Each donor nerve option has unique benefits and drawbacks, and there is no universal consensus on one option that is ideal for all scenarios. The CFNG and the masseteric nerve are currently the most frequently utilized options. The CFNG, which utilizes midfacial branches of the contralateral facial nerve, has the potential of creating a spontaneous and synchronous smile. However, it has lower reliability and less oral commissure excursion than other donor nerves ${ }^{[8,13,18]}$. In contrast, the masseteric nerve, a branch of the trigeminal nerve, contains a greater axonal load and more reliable oral commissure excursion, but at the expense of spontaneity ${ }^{[8,19]}$. Additional considerations when comparing CFNG and masseteric nerves are the potential need for multi-stage surgery and the time needed to achieve movement ${ }^{[20,21]}$. Other principles that guide the choice of donor nerve are availability and donor site morbidity. In this review, we will summarize the current literature on options for GFMT innervation and discuss the advantages and disadvantages in the context of smile excursion, spontaneity, reliability, timing, and other pertinent outcomes in adults and children. There are other important surgical considerations for GFMT that affect smile outcomes that are outside the scope of this review, such as muscle bulk, orientation, and vector at inset, as well as length and tension of the muscle at inset. Relevant publications were identified from the Medline database using the following search terms: gracilis, gracilis innervation, facial reanimation, smile reanimation. Additional articles were then identified by crossreferencing initial search results.

\section{MASSETERIC NERVE TRANSFER}

The masseteric nerve has gained popularity in recent decades as one of the preferred sources of innervation for GFMT due to its reliability, ability to achieve oral commissure excursion, need for only a single stage, and fast onset of movement ${ }^{[8-10,18,22]}$. This technique was first described by Zuker et al $^{\left[{ }^{[11]}\right.}$ in 2000, who utilized the masseteric nerve as the donor source for bilateral GFMT in 10 children with Moebius syndrome causing bilateral facial paralysis. The masseteric nerve arises from the anterior division of the mandibular branch of the trigeminal nerve, providing motor supply to the masseter. Surgically, the nerve can be identified in the sub-zygomatic triangle, bounded by the sigmoid notch of the mandible inferiorly and the zygomatic arch superiorly. The nerve can usually be found within the masseter muscle about $1 \mathrm{~cm}$ inferior to the arch and $3 \mathrm{~cm}$ anterior to the tragus ${ }^{[20]}$. It typically courses obliquely or parallel to the zygomatic arch and can be located in the middle of the muscle about 10 to $15 \mathrm{~mm}$ deep to the parotidomasseteric fascia ${ }^{[7,20]}$. Once identified, it can be traced proximally and distally before being divided just before it branches within the muscle. It can then be transposed superficially for coaptation to a recipient nerve. Notably, the masseteric nerve is often spared in Moebius syndrome, making it a good option for a nerve donor, whereas the facial and hypoglossal nerves can be compromised.

One of the main advantages of the masseteric nerve as a donor source for the GFMT lies in the power that it provides, yielding greater oral commissure excursion when compared to the $\mathrm{CFNG}^{[8,18,19,22]}$. Bhama et al. ${ }^{[18]}$ assessed 154 GFMTs performed for facial reanimation in adults and children between ages 8 and 60 and 


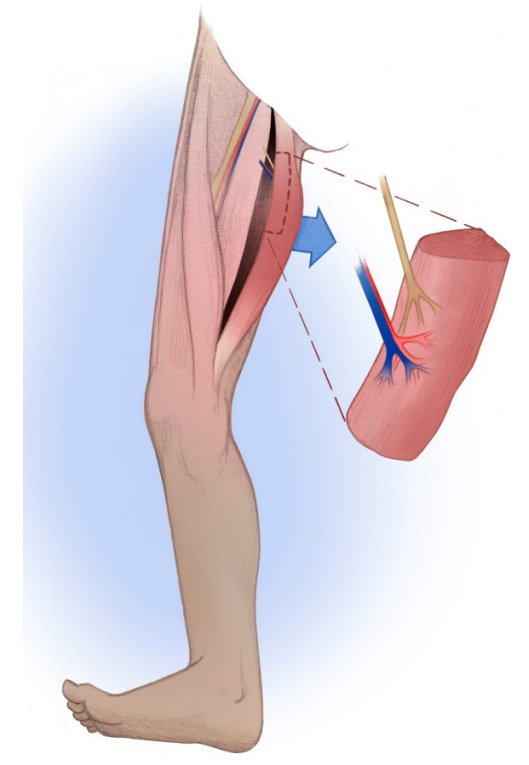

Figure 1. Anatomy of gracilis free muscle transfer harvest, demonstrating the neurovascular pedicle consisting of a branch of the obturator nerve and the adductor artery and vein branches.

found that those innervated by the masseteric nerve had a mean of $2.2 \mathrm{~mm}$ greater oral commissure excursion than those innervated by the contralateral facial nerve $(8.7 \mathrm{~mm}$ vs. $6.5 \mathrm{~mm})$. Similarly, Bae et al. ${ }^{[8]}$ reported a series of 166 children undergoing GFMT and found that oral commissure excursion in masseteric nerve transfer was $14.2 \mathrm{~mm}$ compared to $7.9 \mathrm{~mm}$ for CFNG. Manktelow assessed 31 GFMTs innervated by the masseteric nerve in patients between ages 16 and 61 and found that the commissure on the reconstructed side moved on average $85 \%$ as much as the normal side, with no significant difference between the two ${ }^{[9]}$.

These notable differences in commissure excursion between the masseteric nerve and CFNG may be attributed to axonal load. A study by Terzis et al. ${ }^{[23]}$ found that patients with donor nerve axonal counts greater than 900 had a greater likelihood of achieving good to excellent results. The masseteric nerve has a shorter distance necessary for axonal growth and requires only a single neurorrhaphy, which leads to a greater throughput of axons into the obturator nerve of the GFMT. One study comparing donor nerve histomorphometry via intra-operative nerve biopsies found that the downstream CFNG during the second stage had an average of 1647 axons $/ \mathrm{mm}^{2}, 76 \%$ less than the distal facial nerve branch biopsied in the first stage. Another study reported the average number of axons at the distal end of the CFNG to be $453 \pm 265^{[23]}$. By contrast, the masseteric nerve demonstrated an average of 5289 axons $/ \mathrm{mm}^{2}$ in one study and $2775 \pm 470$ in a separate study ${ }^{[2,22]}$. When assessed with electromyography (EMG), the masseter muscle itself generates more contractile force than the muscles of facial expression, and therefore the masseteric nerve may also provide more robust stimulation than the facial nerve $\mathrm{e}^{[25,26]}$.

From a timing perspective, the masseteric nerve offers relatively quick reinnervation and the onset of movement of the GFMT ${ }^{[20,21]}$. Manktelow et al. ${ }^{[9]}$ reported reinnervation in about 3-4 months in his cohort of 27 patients undergoing GFMT innervated by the masseteric nerve. Faria et al. ${ }^{[21]}$ reported first contractions observed after 3-6 months, with an average of 3.7 months. This is in contrast to the CFNG, which can take up to two years for maximal results from the time of initial surgery ${ }^{[13]}$. Moreover, GFMT with masseteric nerve innervation can be done as a single-stage procedure, which is more ideal for patients with significant medical comorbidities and operative risk. Meanwhile, a CFNG, when done as a two-stage procedure, will 
have an additional lag time between the first stage and second stage, when the GFMT is actually performed.

The main disadvantage to utilizing the masseteric nerve is its lack of spontaneity and synchronicity with the unaffected side of the face when smiling. Under normal circumstances, the activation of facial muscles to create an emotive smile is generally involuntary and spontaneous. However, in cases of GFMT powered by a masseteric nerve, smiling is typically achieved by voluntarily clenching one's jaw on the affected side, which stimulates muscle contraction. As a result, when an emotive smile is involuntarily elicited on the unaffected side, in response to humor, for instance, achieving a natural-appearing smile on the GFMT side to match synchronously can be challenging and requires training and effort. Several studies have shown that patients undergoing facial reanimation with the masseteric nerve can develop a spontaneous appearing smile with motor re-education ${ }^{[9,19]}$. Manktelow et al. ${ }^{[9]}$ reported 45 GFMTs innervated by the masseteric nerve in adults and found that $89 \%$ of patients reported achieving a spontaneous smile. However, only $37 \%$ of these patients reported a spontaneous smile a majority of the time. When they divided their cohort into younger patients (age 16-32) and older patients (age 34-61), they did not find a significant difference (64\% of the younger cohort routinely achieved a spontaneous smile compared to $54 \%$ of the older cohort $)^{[9]}$. Hontanilla and Cabello ${ }^{[19]}$ reported 36 GFMTs innervated by the masseteric nerve and found that $55.6 \%$ were able to achieve spontaneity, with a larger percentage of women achieving spontaneity (70.6\%) compared to men (42.1\%).

One explanation for the development of spontaneity in GFMT with masseteric nerve innervation as opposed to other non-facial cranial nerves is that the masseteric nerve is commonly activated during a normal smile; EMG activation of the masseter muscle is seen in $40 \%$ of healthy individuals during smile production $^{[27]}$. Additionally, the cortical areas responsible for chewing and smiling are in very close proximity. Buendia et al. ${ }^{[28]}$ assessed patients who underwent facial reanimation using masseteric nerve and demonstrated overlap on functional MRI in the smile and jaw-clench areas of the motor cortex.

It is difficult to evaluate spontaneity in a smile, and a majority of studies rely on patient reports or clinician evaluations. Some clinicians advocate a "tickle test" to stimulate a spontaneous smile and evaluate symmetry in the office. To better evaluate the spontaneity in a smile, Dusseldorp et al. ${ }^{[14]}$ created the Spontaneous Smile Assay (SSA), in which video clips are obtained from patients viewing humorous video clips and rated by blinded observers for symmetry and spontaneity. Using this SSA assay to compare the spontaneity of smile in GFMT innervated by masseteric nerve, CFNG, or both, $20 \%$ of GFMT innervated by masseteric nerve were deemed spontaneous, compared to $75 \%$ for CFNG and $33 \%$ for dual innervation ${ }^{[14]}$. Interestingly, spontaneity was underestimated by clinician ratings in this study. When the SSA was compared to clinician ratings in the office, spontaneity was rated as absent in $40 \%$ of patients and trace in $33.3 \%$ of patients who were noted to have spontaneous smiles on the SSA, highlighting the challenges in evaluating spontaneity in smiles.

\section{CROSS FACIAL NERVE GRAFT}

CFNG was first described by Scaramella ${ }^{[29]}$ and $\operatorname{Smith}^{[30]}$ in 1971 . The original technique, in which a sural nerve graft was coapted between facial nerves on the unaffected and paralyzed sides of the face, produced limited facial movement. It was not popularized until 1976 when Harii modified the procedure by coapting the nerve graft to a GFMT in a two-stage procedure ${ }^{[2]}$. The primary advantage of the two-stage technique is that time is allowed for axonal growth to occur through the CFNG prior to GFMT, such that viable axons have reached the free distal end of the nerve graft by the time of coaptation. This leads to less time to innervation of the GFMT and reduced wasting from denervation atrophy. 
In the first stage of a two-stage CFNG, the donor facial nerve branch on the unaffected side of the face is coapted to a cable graft. In the second stage, after allowing time for axonal growth, the distal end of the cable graft is then coapted to the target for reinnervation, such as the obturator nerve of a GFMT. The most commonly used nerve for the cable graft in a CFNG is the sural nerve [Figure 2], as its length, ease of harvesting, and minimal donor site morbidity make it ideal for this purpose. During the first stage of the CFNG, a suitable donor midfacial branch of the facial nerve is identified on the non-paralyzed side of the face with satisfactory stimulation of the lip elevators. It is important to choose a donor facial nerve branch of enough size to provide adequate axonal load. Extensive arborization of the facial nerve branches prevents paralysis on the donor side. If concerned, the surgeon can identify redundant innervation of the lip elevators via an adjacent facial nerve branch prior to dividing the donor nerve. Traditionally, the more distal (closer to the ankle) end of the sural nerve is preferably used for this proximal coaptation to avoid eventual loss of regenerated axons to the inherent branching pattern of the nerve graft. The distal end of the CFNG is tunneled subcutaneously from the donor side of the face to the paralyzed side of the face out through a small upper sublabial incision. The nerve is then allowed to grow through the cable graft, and the second stage is performed when the regenerated axons have reached the distal end of the cable graft. The mean interval between the two stages of the operation typically ranges between 8 to 12 months in adults and 6 to 9 months in children ${ }^{[3,4,13]}$. This timeline depends on the rate of facial axonal regeneration through the nerve graft, which can be followed clinically using the progression of the Tinel sign through the length of the graft. After the second stage has been performed, reinnervation of the GFMT commences. Faria et al. ${ }^{[2]}$ assessed 58 patients between ages 5 to 63 (mean age 28) with a GFMT innervated by a CFNG and noted first contractions after 6 to 15 months with a mean of 11 months. With this timeline, it can be upwards of two years between a patient's initial stage of CFNG and experiencing the full benefits of the GFMT procedure.

Using a CFNG to innervate the GFMT has the potential advantage of restoring a smile that is spontaneous and coordinated with the contralateral side and is considered by some as the only option that produces a spontaneous smile in patients with complete flaccid facial paralysis ${ }^{[13,19,21]}$. As previously mentioned, videography for the SSA found that 75\% of patients with CFNG-innervated GFMT had spontaneous smiles compared to $20 \%$ of patients with masseteric nerve-innervated GFMT ${ }^{[14]}$. Similar differences in spontaneity based on innervation have been identified by other groups. Faria et al. ${ }^{[21]}$ compared 58 patients with GFMT innervated by CFNG and 22 patients innervated with masseteric nerve, and found that $34 \%$ of patients undergoing CFNG were able to smile spontaneously compared to $0 \%$ of the masseteric nerve patients. Similarly, Gousheh et al. ${ }^{[13]}$ reported that all 505 patients who underwent GFMT innervated by CFNG were able to achieve a spontaneous smile post-operatively. In contrast, none of the patients in groups innervated by other nerves ( 26 hypoglossal, 4 spinal accessory) were able to achieve a spontaneous smile, although the masseteric nerve was not considered in this cohort.

One disadvantage of the CFNG is that it is less reliable when compared to other donor nerves ${ }^{[3,9,13]}$. Bhama et al. ${ }^{[18]}$ reported on 127 GFMT for smile reanimation in patients ages 6 to 80 years old and identified decreased oral commissure excursion with CFNG innervation compared to masseteric nerve innervation $(6.5 \pm 2.9 \mathrm{~mm}$ vs. $8.7 \pm 3.5 \mathrm{~mm})$. Hontanilla and Cabello ${ }^{[19]}$ assessed 41 patients (mean age 42$)$ with complete facial paralysis undergoing GFMT innervated by a CFNG and found that patients regained $5.1 \mathrm{~mm}$ of commissural elevation during a smile. When they compared outcomes by innervation, masseteric nerveinnervated GFMT had 40\% more oral commissure excursion than flaps innervated by the CFNG. Ylä-Kotola et al. ${ }^{[31]}$ evaluated 27 patients aged 7 to 65 (mean age 40 ) undergoing a free tissue transfer innervated by CFNG ( 11 underwent GFMT). The average follow-up in the study was 8.5 years. They found that $78 \%$ of patients thought their quality of life had improved, while $22 \%$ believed the reanimation had no effect. 


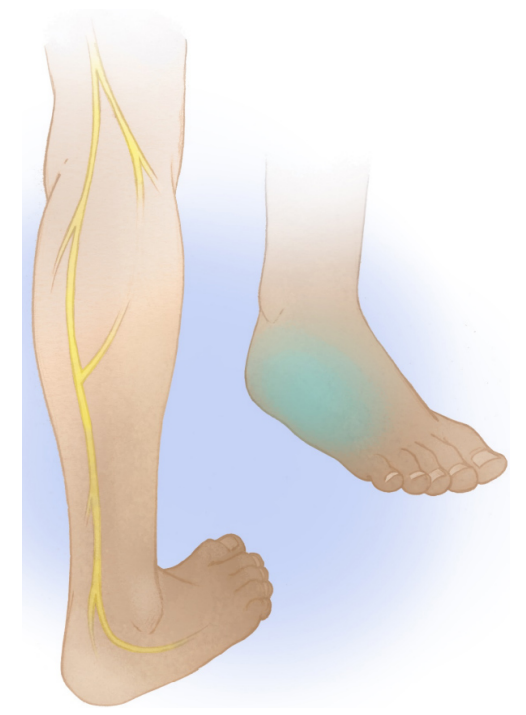

Figure 2. The sural nerve is a cutaneous sensory nerve providing sensation to the posterolateral leg and lateral foot, heel, and ankle.

Despite the drawback of more limited oral commissure movement, there are reports with the CFNG resulting in greater postoperative symmetry during smile than other donor nerves. While this may seem to contradict the data above, symmetry is actually measured separately from oral commissure excursion. The excursion is typically measured as the distance the oral commissure changes when smiling, whereas symmetry is measured as the difference in excursion between the healthy side and the operated side. Bhama et al. ${ }^{[18]}$ reported that while patients innervated by the CFNG had less excursion when compared to the masseteric nerve, they experienced better post-operative symmetry by about $1.8 \mathrm{~mm}$. They attributed this difference to a common neural origin for the zygomaticus major on the unaffected side and the GFMT on the paralyzed side ${ }^{[32]}$. Snyder-Warwick et al. ${ }^{[22]}$ assessed 68 GFMT performed in children with an average of 10 years of age and found that both CFNG and masseteric nerve innervation improved symmetry in oral commissure excursion during a smile. CFNG patients were experiencing an average of $6.5 \mathrm{~mm}$ of improvement in excursion symmetry, whereas the masseteric patients had no significant change in oral commissure excursion symmetry. However, this finding was likely because the majority of patients treated with GFMT with masseteric nerve innervation had bilateral facial paralysis, and therefore had less baseline pre-operative smile asymmetry.

There are differences between outcomes in adults $v s$. children undergoing GFMT innervated by CFNG, with children typically achieving better results. This is likely due to the decreased axonal regeneration achieved in older individuals. A recent study found a relationship between time to achieve Tinel sign in CFNG and age of the patient, implying a slower rate of nerve regeneration in older patients ${ }^{[33]}$. Hembd et al. ${ }^{[3]}$ examined cadaveric facial nerves and found a significant negative correlation between age and axonal load. Numerous other studies conducted in animals and humans have shown axonal regeneration and total axon counts decrease with age ${ }^{[25,35-37]}$. Faria et al. ${ }^{[21]}$ found that in 58 patients undergoing GFMT innervated by a CFNG, the mean age among patients with excellent or good results was significantly lower than in patients with fair or poor results (19.8 years vs. 36.5 years). Terzis et al. ${ }^{[38]}$ performed 26 GFMT innervated by the CFNG and found that patients younger than 35 had significantly better results than older patients. 


\section{COMBINATION OF DONOR NERVES}

Dual-innervation for GFMT is a promising avenue for the future of dynamic smile reanimation, potentially taking advantage of the strengths of different donor nerve sources while also compensating for their weaknesses. The most common combination of dual-innervation is the use of the masseteric nerve plus CFNG [Figure 3], which could provide increased excursion from the masseteric nerve and spontaneity from the $\mathrm{CFNG}^{[16]}$. However, while dual-innervation continues to gain popularity, it also remains difficult to determine the success of each donor nerve in innervating the GFMT.

In 2009, Watanabe et al ${ }^{[39]}$ first described providing dual innervation of a free latissimus dorsi muscle transfer using the masseteric nerve and a CFNG, with evidence of dual innervation on EMG in three patients. Several years later, Biglioli et al. ${ }^{[16]}$ then described this same technique of dual innervation in four patients using the GFMT instead of the latissimus dorsi muscle. This was performed in a single-stage procedure, where the masseteric nerve was coapted to the obturator nerve in an end-to-end fashion while the CFNG was coapted via an epineural window (without transecting axons) distal to the masseteric nerve coaptation. Although this was a small cohort, all four patients were able to achieve good smile results.

Cardenas-Mejia et al. ${ }^{[15]}$ performed GFMT dually innervated by the masseteric nerve and CFNG in 9 adult patients utilizing a two-stage technique for the CFNG. This was done with an end-to-end coaptation between the CFNG and the distal end of the obturator nerve. The masseteric nerve was connected more proximally $1 \mathrm{~cm}$ distal to the gracilis muscle. In the study, all patients recovered voluntary and spontaneous smile abilities at an average of 8.8 weeks as measured by pre- and post-operative videos analyzed by the surgeon $^{[15]}$. Mcneely et al. ${ }^{[40]}$ assessed 9 children (mean age 8.6) who underwent a two-stage GFMT also innervated by the CFNG and masseteric nerve, both of which were coapted to the obturator nerve in an end-to-end fashion. They noted that all patients achieved spontaneous smiles 3 to 7 months after GFMT, assessed by the surgeon at follow-up. The average time between stages was 13.3 months. Another study by Sforza et al..$^{[41]}$ of 13 patients who underwent a single-stage GFMT dually innervated with masseteric nerve (end-to-end) and CFNG (end-to-side epineural window, distal to masseteric nerve coaptation) reported that $70 \%$ of patients achieved spontaneous smile at 1-2 years post-operatively. In the study $15 \%$ of patients did not achieve any smile reanimation. The authors did not specify if failures were due to axonal ingrowth disturbance or microvascular impairments.

There is currently limited data comparing single-stage and two-stage CFNG during dual innervation GFMT. However, two-stage surgery ensures that the distal ends of both the masseteric nerve and CFNG have viable axons when coaptation to the GFMT. Theoretically, this would allow for more synchronous innervation of motor units in the GFMT from both sources. However, if single-stage surgery is found to achieve comparable outcomes, it would obviate the need for multiple operations and potentially allow patients to enjoy the restoration of smiles sooner. Dusseldorp et al. ${ }^{[14]}$ reported a retrospective case-control study comparing spontaneity in 24 single-stage innervation GFMT with either CFNG or masseteric nerve alone vs. 25 dually innervated (CFNG plus masseteric nerve) GFMT. Dual innervation was achieved either through an interfascicular split, y-shaped neurorrhaphy, or a proximal epineural window end-to-side CFNG coaptation and a distal end-to-end masseteric coaptation. Spontaneity was measured using the previously described SSA, and the authors found that spontaneity in dually innervated patients (33\%) was superior to that of the masseter alone patients (20\%) but inferior to that of the CFNG alone patients (75\%), although there was no statistically significant difference detected between groups. Interestingly, there were also no significant differences in oral commissure excursion or eFACE scores between groups. 


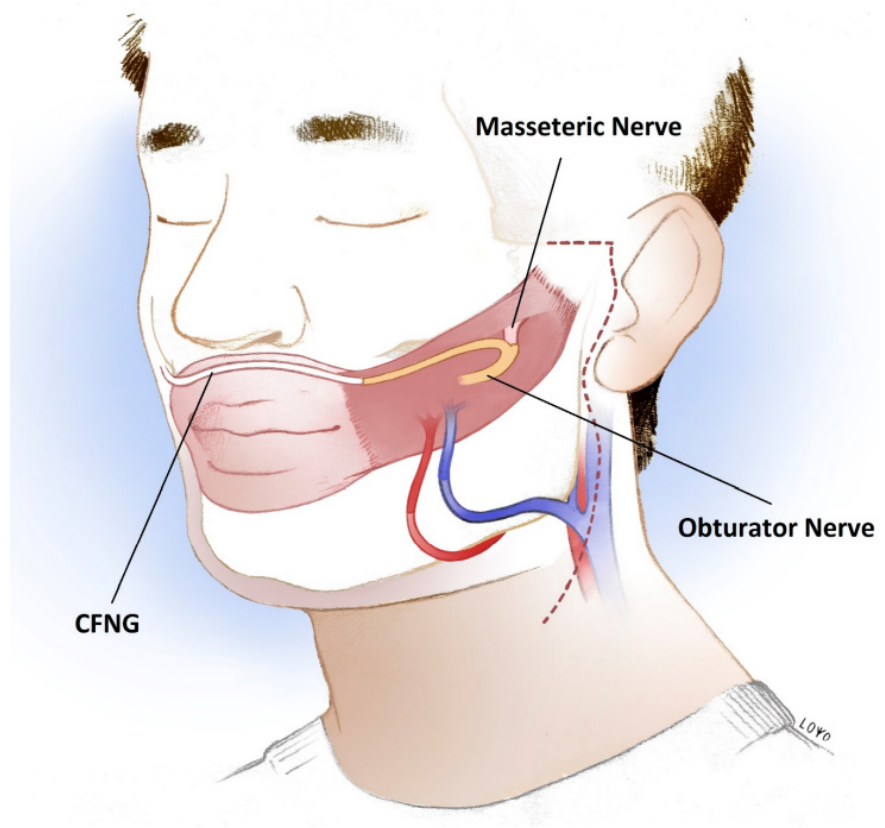

Figure 3. Dual innervation of a gracilis free muscle transfer achieved by cross-facial nerve graft (coapted distally end-to-end with the obturator nerve) plus masseteric nerve (coapted proximally end-to-end with the obturator nerve). CFNG: cross-facial nerve graft.

The physiologic basis of dual innervation is still not fully elucidated. Some authors posit that certain nerves provide greater contributions to spontaneity while others to oral commissure excursion. However, determining the contribution of individual nerves remains challenging. Furthermore, the effects of competition between two innervating nerve sources also remain to be understood ${ }^{[42]}$. Nevertheless, dual innervation for GFMT has demonstrated promising results worthy of further investigation. Figures 4 and 5 show preoperative and postoperative photos of two patients who underwent dual innervation GFMT.

\section{OTHER DONOR NERVE OPTIONS}

In addition to the trigeminal nerve and CFNG, the SAN and the hypoglossal nerve can also be used to innervate a GFMT. Because of higher donor nerve morbidity, these are typically reserved for situations where the options mentioned above are not available. Nerve availability is a particularly important consideration in patients with Moebius syndrome who often experience several cranial neuropathies. In patients with Moebius syndrome, 65\% have contralateral facial nerve dysfunction, $48 \%$ have hypoglossal nerve dysfunction, and $6 \%$ have SAN dysfunction ${ }^{[43,44]}$. The trigeminal nerve can also be involved; Cardenas-Mejia et al..$^{[45]}$ found that $7.5 \%$ of patients with Moebius syndrome also had an abnormality of the trigeminal nerve when assessed with EMG.

In GFMT innervated by SAN, $10 \mathrm{~cm}$ of the SAN are dissected and tunneled beneath the platysma muscle to reach the GFM. The SAN has approximately 1400 axons available for innervation of the muscle transplant ${ }^{[46]}$. However, a major disadvantage to using the SAN is donor site morbidity with ipsilateral trapezius weakness and shoulder pain ${ }^{[47,48]}$. Chuang et al. ${ }^{[6]}$ performed 56 GFMT innervated by the SAN and found that a majority of patients were able to achieve a full dental display with a smile after 6-12 months. Forty-five percent of patients achieved a spontaneous smile as measured by a "tickle test", whereby if a smile could be elicited directly by tickling, it was classified as spontaneous. This was comparable to their cohort of patients undergoing GFMT innervated by a CFNG. They also found that SAN innervated GFMT started moving at approximately 4 months post-operatively and reached optimal results between the first- and 


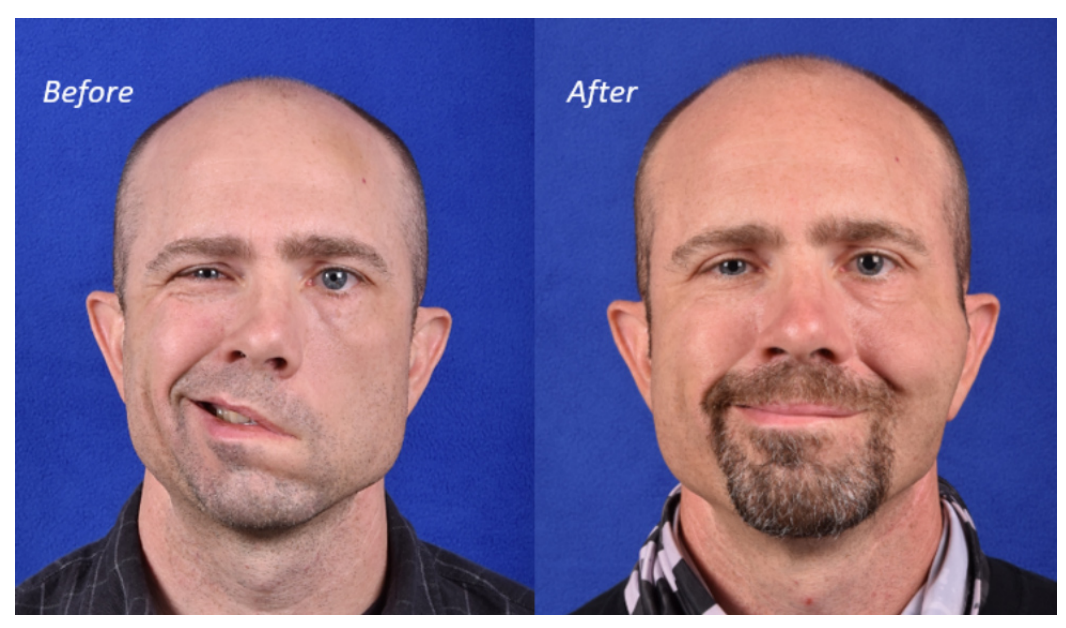

Figure 4. A 46-year-old male who underwent single-stage dual innervation gracilis free muscle transfer with cross-facial nerve graft and masseteric nerve. The post-operative photo was taken 8 months after surgery.

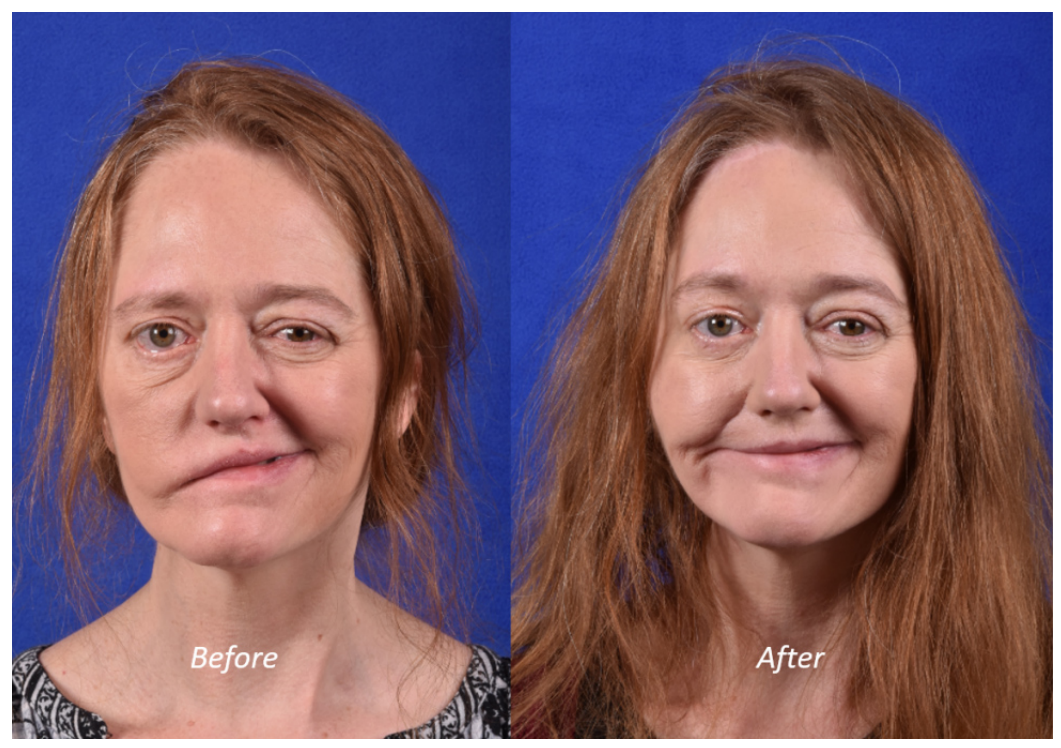

Figure 5. A 46-year-old woman who underwent two-stage dual innervation gracilis free muscle transfer with cross-facial nerve graft and masseteric nerve. The post-operative photo was taken 8 months after surgery.

second-year post-reanimation. This was faster than CFNG-innervated GFMT, which took 2 to 3 years to achieve optimal results, and slower than the masseteric nerve group, which took 6 months to 1 year. Interestingly, the CFNG-innervated GFMT cohort reported the highest patient satisfaction scores, followed by SAN and then masseteric nerve ${ }^{[6]}$. Nevertheless, because of potentially high donor site morbidity, the SAN is seldom used as a source for innervation.

Conley and Baker ${ }^{[49]}$ popularized hypoglossal-facial coaptation. When the entire hypoglossal nerve is sacrificed for facial reanimation, substantial donor site morbidity has been reported in the form of hemilingual atrophy and deviation leading to dysarthria and dysphagia, and involuntary facial movement and spasm with tongue movement ${ }^{[13]}$. Given these issues, several techniques have been developed to preserve the hypoglossal nerve function, such as partial nerve transfers and minimizing hypoglossal manipulation with interposition cable grafts ${ }^{[50]}$. Functionally, patients with GFMT innervated by the 
hypoglossal nerve need to push their tongue against their lower teeth to induce a smile, and there is a low likelihood of patients being able to achieve spontaneous smile through cortical adaptation ${ }^{[13]}$. Nevertheless, hypoglossal innervation of GFMT may provide better excursion and shorter time to achieving movement when compared to CFNG, likely due to the higher axonal $(9778 \pm 1516)^{[51]}$. Hypoglossal innervation can also provide a good resting tone and may be used in conjunction with other neural sources, including $\mathrm{CFNG}^{[52]}$. Ueda et al. ${ }^{[53]}$ performed 17 free muscle transplantations (12 latissimus muscle transfers, 4 GFMT, and 1 rectus abdominis muscle transfer) innervated by the hypoglossal nerve in patients between 22 and 74 years of age. This procedure was chosen to minimize the operative time in older individuals (12 patients over age 60) and to rehabilitate three younger patients who had undergone a CFNG with no subsequent movement. The initial movement of the free muscle transplant was noted from 4 to 9 months post-operatively. A majority achieved a "good" function $(n=13)$ with synchronous and natural expressions, and the remaining patients achieved a "satisfactory" function $(n=4)$ with less synchronicity. The study reported tongue atrophy in all patients, with more atrophy when a larger portion of the hypoglossal was utilized. Interestingly, there was no significant difference in functional outcome between patients with different sections of hypoglossal nerve used. Therefore, morbidity could likely be reduced by utilizing lower branches that innervate only suprahyoid musculature and avoiding branches innervating lingual musculature ${ }^{[53]}$. Hontanilla and Aubá ${ }^{[54]}$ also reported on a single 30-year-old patient who had bilateral facial nerve paralysis after resection of a brain tumor, precluding availability of the facial or masseteric nerves. The surgeons chose to perform bilateral GFMT innervated by hypoglossal in two separate procedures, each utilizing direct coaptation of the obturator nerve to the hypoglossal nerve. This patient was not reported to experience lingual atrophy or functional deficits from donor site morbidity ${ }^{[54]}$.

\section{AREAS FOR FUTURE INVESTIGATION}

One of the greatest hurdles in the current literature for facial reanimation is the heterogeneity of outcome measures that exist. While there is a growing body of research assessing the various sources of innervation for GFMT, the ability to compare or aggregate data across different studies remains limited. In 2020, Vila et al. ${ }^{[55]}$ performed the only systematic review and meta-analysis of outcomes for GFMT based on different donor nerves. They included ten studies in their systematic review, each using excursion and symmetry as outcome measures. Three of these studies reported outcomes using FACE-gram and were ultimately included in their meta-analysis, which found that excursion was significantly higher in GFMT with masseteric nerve innervation than CFNG. At the same time, symmetry was not significantly different between the two groups. Unfortunately, spontaneity could not be included in the meta-analysis due to heterogeneity in outcome measures, although the data suggested improved spontaneity with CFNG. Overall, they concluded that they were unable to make definitive recommendations regarding the optimal donor nerve for GFMT due to a lack of uniform reporting measures.

Adoption of universal outcome measures in the study of facial reanimation would be groundbreaking in our ability to compare and reproduce future investigations. To this end, Sir Charles Bell's Society for the treatment of facial paralysis advocates for the use of a common facial analysis measurement software ${ }^{[56]}$ and a quantitative assay for smile spontaneity ${ }^{[14,57]}$. In terms of donor nerve choice for GFMT, further study is needed to assess the outcomes of single-stage vs. two-stage dually innervated GFMT and the optimal patterns of dual nerve coaptation that optimize the individual benefits of masseteric nerve and CFNG donors.

\section{CONCLUSIONS}

Dynamic smile restoration is crucial to treating the functional and aesthetic impairment resulting from facial paralysis. For longstanding or congenital paralysis in which the native facial mimetic musculature is 
Table 1. Summary of gracilis free muscle transfer donor nerve options

\begin{tabular}{|c|c|c|c|c|c|c|c|}
\hline Donor nerve & $\begin{array}{l}\text { Estimated } \\
\text { axonal load }\end{array}$ & $\begin{array}{l}\text { Time to initial } \\
\text { movement }\end{array}$ & $\begin{array}{l}\text { Time to stable } \\
\text { movement }\end{array}$ & $\begin{array}{l}\text { Oral commissure } \\
\text { excursion }\end{array}$ & Spontaneity & Stages & Morbidity \\
\hline $\begin{array}{l}\text { Masseteric nerve } \\
\text { (trigeminal nerve branch, } \\
\text { CN V) }\end{array}$ & $\begin{array}{l}5289^{[22]} \\
2775 \pm 470^{[24]}\end{array}$ & $\begin{array}{l}\text { 3-6 months } \\
\text { (average } 3.7{ }^{[21]} \\
3-4 \text { months }^{[9]} \\
3-4 \text { months }^{[6]}\end{array}$ & $\begin{array}{l}9 \text { months }^{[18]} \\
<6 \text { months }^{[6]}\end{array}$ & $\begin{array}{l}8.7 \pm 3.5 \mathrm{~mm}^{[18]} \\
13.0 \pm 4.7 \mathrm{~mm}^{[9]} \\
7.7 \pm 2.8 \mathrm{~mm}^{[3]} \\
8.1 \pm 4.0 \mathrm{~mm}^{[22]}\end{array}$ & $\begin{array}{l}0 \%^{[21]} \\
20 \%^{[14]} \\
0 \%{ }^{[13]} \\
55.5 \%{ }^{[19]} \\
\text { Women: } \\
70.6 \% \\
\text { Men: } 42.1 \%^{[19]}\end{array}$ & One & $\begin{array}{l}\text { Masseter muscle atrophy without dysarthria; rare TMJ } \\
\text { dysfunction; prandial facial movement rarely considered } \\
\text { bothersome }\end{array}$ \\
\hline $\begin{array}{l}\text { Cross facial nerve graft } \\
\text { (contralateral CN VII) }\end{array}$ & $\begin{array}{l}1647 / \mathrm{mm}^{2[22]} \\
453 \pm 265^{[23]}\end{array}$ & $\begin{array}{l}\text { 6-15 months } \\
{\text { (average } 11.1)^{[21]}} \\
\text { Children: } 3.5 \\
\text { months } \\
\text { Adults: } 5-6 \\
\text { months }{ }^{[20]} \\
14-17 \text { months } \\
{\text { (average } 15.4)^{[12]}}{ }^{4}-6 \text { months } \\
\text { 46] } \\
4-8 \text { months }^{[58]}\end{array}$ & $\begin{array}{l}18 \text { months }^{[18]} \\
12-24 \text { months }^{[6]}\end{array}$ & $\begin{array}{l}14.6 \pm 6.2 \mathrm{~mm}^{[12]} \\
7.9 \pm 3.9 \mathrm{~mm}^{[8]} \\
6.5 \pm 2.9^{[18]} \\
5.1 \pm 2.6 \mathrm{~mm}^{[3]} \\
4.1 \pm 2.9 \mathrm{~mm}^{[22]}\end{array}$ & $\begin{array}{l}34 \%^{[21]} \\
75 \%^{[14]} \\
100 \%^{[13]}\end{array}$ & $\begin{array}{l}\text { Typically two, can be } \\
\text { done as a single stage }\end{array}$ & Sensory disturbance with sural nerve harvest \\
\hline $\begin{array}{l}\text { Spinal accessory nerve (CN } \\
\mathrm{XI})\end{array}$ & $1400^{[46]}$ & 4 months $^{[6]}$ & $<12$ months $^{[6]}$ & Not reported & $45 \%{ }^{[6]}$ & One & Ipsilateral trapezius weakness and shoulder pain \\
\hline Hypoglossal nerve (CN XII) & $9778 \pm 1516^{[51]}$ & $\begin{array}{l}3-6 \text { months } \\
{\text { (average } 4.6)^{[12]}}^{4-9 \text { months }^{[53]}}\end{array}$ & Not reported & $\begin{array}{l}9-29 \mathrm{~mm}^{[12]} \\
19.2 \pm 6.3 \mathrm{~mm}^{[12]}\end{array}$ & None reported & One & Hemitongue atrophy, speech and swallowing dysfunction \\
\hline
\end{tabular}

CN: Cranial nerve; TMJ: temporomandibular joint.

no longer viable, GFMT is the gold standard in smile restoration. Various donor nerve options exist for innervating GFMT, most commonly the ipsilateral masseteric nerve and CFNG based on a midfacial branch of the contralateral facial nerve. In general, masseteric nerve innervation provides superior excursion and faster onset of smile movement after surgery, while the CFNG offers better spontaneity of smile. In patients for whom masseteric nerve or CFNG are not options, other donor nerves exist for innervation of the GFMT. A summary of the various donor nerves discussed in this review is shown in Table 1. Dual innervation with both masseteric nerve and CFNG has yielded promising results in GFMT, taking advantage of the benefits of each donor source. Selecting an optimal donor nerve for GFMT ultimately depends on individual patient factors, including etiology of the facial paralysis, availability of donor options, age, comorbidities, and patient's desires. Further research is needed to determine the optimal staging and pattern of coaptation for dually innervated GFMT. Most importantly, standardization of outcome measures for research in the field of facial paralysis will be crucial to effectively compare and reproduce future results as our body of literature continues to grow. 


\section{DECLARATIONS}

\section{Authors' contributions}

Literature review, manuscript preparation, submission: Gossett K

Literature review, manuscript preparation: Chen D, Loyo M

\section{Availability of data and materials}

We have created and copyrighted all included images.

\section{Financial support and sponsorship}

None.

\section{Conflicts of interest}

All authors declared that there are no conflicts of interest.

\section{Ethical approval and consent to participate}

Not applicable.

\section{Consent for publication}

The authors have consent from patients to use all included photographs.

\section{Copyright}

(c) The Author(s) 2021.

\section{REFERENCES}

1. Bradbury ET, Simons W, Sanders R. Psychological and social factors in reconstructive surgery for hemi-facial palsy. J Plast Reconstr Aesthet Surg 2006;59:272-8. DOI PubMed

2. Harii K, Ohmori K, Torii S. Free gracilis muscle transplantation, with microneurovascular anastomoses for the treatment of facial paralysis. A preliminary report. Plast Reconstr Surg 1976;57:133-43. DOI PubMed

3. Hontanilla B, Marre D, Cabello Á. Facial reanimation with gracilis muscle transfer neurotized to cross-facial nerve graft versus masseteric nerve: a comparative study using the FACIAL CLIMA evaluating system. Plast Reconstr Surg 2013;131:1241-52. DOI PubMed

4. Peng GL, Azizzadeh B. Cross-facial nerve grafting for facial reanimation. Facial Plast Surg 2015;31:128-33. DOI PubMed

5. O'brien BM, Franklin JD, Morrison WA. Cross-facial nerve grafts and microneurovascular free muscle transfer for long established facial palsy. Br J Plast Surg 1980;33:202-15. DOI PubMed

6. Chuang DC, Lu JC, Chang TN, Laurence VG. Comparison of functional results after cross-face nerve graft-, spinal accessory nerve-, and masseter nerve-innervated gracilis for facial paralysis reconstruction: the chang gung experience. Ann Plast Surg 2018;81:S21-9. DOI PubMed

7. Henstrom DK. Masseteric nerve use in facial reanimation. Curr Opin Otolaryngol Head Neck Surg 2014;22:284-90. DOI PubMed

8. Bae YC, Zuker RM, Manktelow RT, Wade S. A comparison of commissure excursion following gracilis muscle transplantation for facial paralysis using a cross-face nerve graft versus the motor nerve to the masseter nerve. Plast Reconstr Surg 2006;117:2407-13. DOI PubMed

9. Manktelow RT, Tomat LR, Zuker RM, Chang M. Smile reconstruction in adults with free muscle transfer innervated by the masseter motor nerve: effectiveness and cerebral adaptation. Plast Reconstr Surg 2006;118:885-99. DOI PubMed

10. Oh TS, Kim HB, Choi JW, Jeong WS. Facial reanimation with masseter nerve-innervated free gracilis muscle transfer in established facial palsy patients. Arch Plast Surg 2019;46:122-8. DOI PubMed PMC

11. Zuker RM, Goldberg CS, Manktelow RT. Facial animation in children with Möbius syndrome after segmental gracilis muscle transplant. Plast Reconstr Surg 2000;106:1-8; discussion 9. DOI PubMed

12. Amer TA, El Kholy MS. The split hypoglossal nerve versus the cross-face nerve graft to supply the free functional muscle transfer for facial reanimation: a comparative study. J Plast Reconstr Aesthet Surg 2018;71:750-7. DOI PubMed

13. Gousheh J, Arasteh E. Treatment of facial paralysis: dynamic reanimation of spontaneous facial expression-apropos of 655 patients. Plast Reconstr Surg 2011;128:693e-703e. DOI PubMed

14. Dusseldorp JR, van Veen MM, Guarin DL, Quatela O, Jowett N, Hadlock TA. Spontaneity assessment in dually innervated gracilis smile reanimation surgery. JAMA Facial Plast Surg 2019;21:551-7. DOI PubMed PMC

15. Cardenas-Mejia A, Covarrubias-Ramirez JV, Bello-Margolis A, Rozen S. Double innervated free functional muscle transfer for facial reanimation. J Plast Surg Hand Surg 2015;49:183-8. DOI PubMed

16. Biglioli F, Colombo V, Tarabbia F, et al. Double innervation in free-flap surgery for long-standing facial paralysis. J Plast Reconstr 
Aesthet Surg 2012;65:1343-9. DOI PubMed

17. Win TS, Tzafetta K. Power and coordination for facial reanimation - dual innervation of free gracilis transfer using masseteric nerve and cross-facial nerve graft. Plast Reconstr Surg 2014;134:13. DOI

18. Bhama PK, Weinberg JS, Lindsay RW, Hohman MH, Cheney ML, Hadlock TA. Objective outcomes analysis following microvascular gracilis transfer for facial reanimation: a review of 10 years' experience. JAMA Facial Plast Surg 2014;16:85-92. DOI PubMed

19. Hontanilla B, Cabello A. Spontaneity of smile after facial paralysis rehabilitation when using a non-facial donor nerve. $J$ Craniomaxillofac Surg 2016;44:1305-9. DOI PubMed

20. Bianchi B, Copelli C, Ferrari S, Ferri A, Bailleul C, Sesenna E. Facial animation with free-muscle transfer innervated by the masseter motor nerve in unilateral facial paralysis. J Oral Maxillofac Surg 2010;68:1524-9. DOI PubMed

21. Faria JC, Scopel GP, Busnardo FF, Ferreira MC. Nerve sources for facial reanimation with muscle transplant in patients with unilateral facial palsy: clinical analysis of 3 techniques. Ann Plast Surg 2007;59:87-91. DOI PubMed

22. Snyder-Warwick AK, Fattah AY, Zive L, Halliday W, Borschel GH, Zuker RM. The degree of facial movement following microvascular muscle transfer in pediatric facial reanimation depends on donor motor nerve axonal density. Plast Reconstr Surg 2015;135:370e-81e. DOI PubMed

23. Terzis JK, Wang W, Zhao Y. Effect of axonal load on the functional and aesthetic outcomes of the cross-facial nerve graft procedure for facial reanimation. Plast Reconstr Surg 2009;124:1499-512. DOI PubMed

24. Borschel GH, Kawamura DH, Kasukurthi R, Hunter DA, Zuker RM, Woo AS. The motor nerve to the masseter muscle: an anatomic and histomorphometric study to facilitate its use in facial reanimation. J Plast Reconstr Aesthet Surg 2012;65:363-6. DOI PubMed

25. Jacobs JM, Laing JH, Harrison DH. Regeneration through a long nerve graft used in the correction of facial palsy. A qualitative and quantitative study. Brain 1996;119:271-9. DOI PubMed

26. Boxtel A, Goudswaard P, van der Molen GM, van den Bosch WE. Changes in electromyogram power spectra of facial and jawelevator muscles during fatigue. J Appl Physiol Respir Environ Exerc Physiol 1983;54:51-8. DOI PubMed

27. Schaverien M, Moran G, Stewart K, Addison P. Activation of the masseter muscle during normal smile production and the implications for dynamic reanimation surgery for facial paralysis. J Plast Reconstr Aesthet Surg 2011;64:1585-8. DOI PubMed

28. Buendia J, Loayza FR, Luis EO, Celorrio M, Pastor MA, Hontanilla B. Functional and anatomical basis for brain plasticity in facial palsy rehabilitation using the masseteric nerve. J Plast Reconstr Aesthet Surg 2016;69:417-26. DOI PubMed

29. Scaramella LF. L'anastomosi tra i due nervi facciali. Avialable from: http://pascalfrancis.inist.fr/vibad/index.php?action=getRecordDetail\&idt=PASCAL73347725 [Last accessed on 1 Nov 2021].

30. Smith JW. A new technique of facial animation. In Transactions of the 5th International Congress of Plastic Surgery. London: Butterworth; 1971.

31. Ylä-Kotola TM, Kauhanen MS, Asko-Seljavaara SL. Facial reanimation by transplantation of a microneurovascular muscle: long-term follow-up. Scand J Plast Reconstr Surg Hand Surg 2004;38:272-6. DOI PubMed

32. Lindsay RW, Bhama P, Hadlock TA. Quality-of-life improvement after free gracilis muscle transfer for smile restoration in patients with facial paralysis. JAMA Facial Plast Surg 2014;16:419-24. DOI PubMed

33. Braam MJ, Nicolai JP. Axonal regeneration rate through cross-face nerve grafts. Microsurgery 1993;14:589-91. DOI PubMed

34. Hembd A, Nagarkar P, Perez J, et al. Correlation between facial nerve axonal load and age and its relevance to facial reanimation. Plast Reconstr Surg 2017;139:1459-64. DOI PubMed

35. Oka K, Goto N, Nonaka N, Goto J, Tsurumi T. Nerve fiber analysis and age-related changes of the human mandibular nerve. Okajimas Folia Anat Jpn 2001;78:39-41. DOI PubMed

36. Kondo Y, Moriyama H, Hirai S, Qu N, Itoh M. The relationship between Bell's palsy and morphometric aspects of the facial nerve. Eur Arch Otorhinolaryngol 2012;269:1691-5. DOI PubMed

37. Sturrock RR. Loss of neurons from the motor nucleus of the facial nerve in the ageing mouse brain. J Anat 1988;160:189-94. PubMed PMC

38. Terzis JK, Konofaos P. Experience with 60 adult patients with facial paralysis secondary to tumor extirpation. Plast Reconstr Surg 2012;130:51e-66e. DOI PubMed

39. Watanabe Y, Akizuki T, Ozawa T, Yoshimura K, Agawa K, Ota T. Dual innervation method using one-stage reconstruction with free latissimus dorsi muscle transfer for re-animation of established facial paralysis: simultaneous reinnervation of the ipsilateral masseter motor nerve and the contralateral facial nerve to improve the quality of smile and emotional facial expressions. J Plast Reconstr Aesthet Surg 2009;62:1589-97. DOI PubMed

40. Mcneely MM, Liang F, Makar K, Vercler CJ, Kuzon W. Two-stage dual-nerve facial reanimation: outcomes and complications in a series of pediatric patients. Plast Surg (Oakv) 2020. DOI

41. Sforza C, Frigerio A, Mapelli A, et al. Double-powered free gracilis muscle transfer for smile reanimation: a longitudinal optoelectronic study. J Plast Reconstr Aesthet Surg 2015;68:930-9. DOI PubMed

42. Turney SG, Lichtman JW. Reversing the outcome of synapse elimination at developing neuromuscular junctions in vivo: evidence for synaptic competition and its mechanism. PLoS Biol 2012;10:e1001352. DOI PubMed PMC

43. Picciolini O, Porro M, Cattaneo E, et al. Moebius syndrome: clinical features, diagnosis, management and early intervention. Ital $J$ Pediatr 2016;42:56. DOI PubMed PMC

44. Abramson DL, Cohen MM Jr, Mulliken JB. Möbius syndrome: classification and grading system. Plast Reconstr Surg 1998;102:9617. DOI PubMed

45. Cardenas-Mejia A, Palafox D. Facial reanimation surgery in Möbius syndrome: experience from 76 cases from a tertiary referral hospital in Latin America. Ann Chir Plast Esthet 2018;63:338-42. DOI PubMed 
46. Placheta E, Tinhofer I, Schmid M, et al. The spinal accessory nerve for functional muscle innervation in facial reanimation surgery: an anatomical and histomorphometric study. Ann Plast Surg 2016;77:640-4. DOI PubMed

47. Poe DS, Scher N, Panje WR. Facial reanimation by XI-VII anastomosis without shoulder paralysis. Laryngoscope 1989;99:1040-7. DOI PubMed

48. Ebersold MJ, Quast LM. Long-term results of spinal accessory nerve-facial nerve anastomosis. J Neurosurg 1992;77:51-4. DOI PubMed

49. Conley J, Baker DC. Hypoglossal-facial nerve anastomosis for reinnervation of the paralyzed face. Plast Reconstr Surg 1979;63:63-72. DOI PubMed

50. Atlas MD, Lowinger DS. A new technique for hypoglossal-facial nerve repair. Laryngoscope 1997;107:984-91. DOI PubMed

51. Asaoka K, Sawamura Y, Nagashima M, Fukushima T. Surgical anatomy for direct hypoglossal-facial nerve side-to-end "anastomosis". J Neurosurg 1999;91:268-75. DOI PubMed

52. Yoshioka N. Hypoglossal-facial side-to-end neurorrhaphy with concomitant masseteric-zygomatic nerve branch coaptation and muscle transfer for facial reanimation: technique and case report. Oper Neurosurg (Hagerstown) 2020;19:E230-5. DOI PubMed

53. Ueda K, Harii K, Yamada A. Free neurovascular muscle transplantation for the treatment of facial paralysis using the hypoglossal nerve as a recipient motor source. Plast Reconstr Surg 1994;94:808-17. DOI PubMed

54. Hontanilla B, Aubá C. Smile reconstruction through bilateral muscular transplants neurotized by hypoglossal nerves. J Craniofac Surg 2011;22:845-7. DOI PubMed

55. Vila PM, Kallogjeri D, Yaeger LH, Chi JJ. Powering the gracilis for facial reanimation: a systematic review and meta-analysis of outcomes based on donor nerve. JAMA Otolaryngol Head Neck Surg 2020;146:429-36. DOI PubMed PMC

56. Hadlock TA, Urban LS. Toward a universal, automated facial measurement tool in facial reanimation. Arch Facial Plast Surg 2012;14:277-82. DOI PubMed

57. Iacolucci CM, Banks C, Jowett N, et al. Development and validation of a spontaneous smile assay. JAMA Facial Plast Surg 2015;17:191-6. DOI PubMed

58. Terzis JK, Olivares FS. Long-term outcomes of free-muscle transfer for smile restoration in adults. Plast Reconstr Surg 2009;123:87788. DOI PubMed 